\title{
QSPR study about sampling rates of semipermeable membrane devices for monitoring of organochlorine pesticides in Alps air
}

\author{
ZHU XiuHua $^{1 *}$, DING GuangHui ${ }^{2}$, LEVY Walkiria ${ }^{3}$, JAKOBI Gert $^{3}$, OFFENTHALER Ivo $^{5}$, \\ MOCHE Wolfang ${ }^{5}$, WEISS Peter ${ }^{5} \&$ SCHRAMM Karl-Werner ${ }^{3,4}$ \\ ${ }^{1}$ School of Environmental and Chemical Engineering, Dalian Jiaotong University, Dalian 116028, China; \\ ${ }^{2}$ College of Environmental Science and Engineering, Dalian Maritime University, Dalian 116026, China; \\ ${ }^{3}$ Helmholtz Zentrum München-German Research Center for Environmental Health, Institute of Ecological Chemistry, Ingolstädter Landstr. 1, \\ D-85764 Neuherberg, Munich, Germany; \\ ${ }^{4}$ TUM, Wissenschaftszentrum Weihenstephan fuer Ernaehrung und Landnutzung, Department fuer Biowissenschaftliche Grundlagen, Weihen- \\ stephaner Steig 23, 85350 Freising, Germany; \\ ${ }^{5}$ Umweltbundesamt GmbH, Spittelauer Lände 5, 1090 Wien, Austria
}

Received October 18, 2010; accepted November 22, 2010; published online May 12, 2011

\begin{abstract}
Organochlorine pesticides (OCP) were monitored at the Weissfluhjoch site (Switzerland) and the top of Mt. Sonnblick (Austria) with a low volume active air sampler and semipermeable membrane devices (SPMD). The air sampling rates $\left(R_{\text {air }}\right)$ of the SPMD for OCP were calculated. Statistical tests showed that there was no significant difference between $R_{\text {air }}$ at the two different sampling sites. Quantitative structure-property relationship (QSPR) models of the $R_{\text {air }}$ of the SPMD were developed for OCP using partial least square (PLS) regression. Quantum chemical descriptors computed by the semi-empirical PM6 method were used as predictor variables. The cumulative variance of the dependent variable explained by the PLS components and determined by cross-validation $\left(Q_{\text {cum }}^{2}\right)$ was $>0.818$ for each optimal model. This indicates that the model has good predictive ability and robustness. The $R_{\text {air }}$ of the SPMD for OCP is related to the total energy, the van der Waals area and the total dipole moment of the OCP molecules. The main factors governing $R_{\text {air }}$ values of OCP are intermolecular interactions and the energy required for cavity-formation in dissolution of OCP into triolein of the SPMD. The linear correlation coefficient between predicted and experimental values were all $>0.921$.
\end{abstract}

air sampling rate, semipermeable membrane device, organochlorine pesticides, quantitative structure-property relationship

Citation: Zhu X H, Ding G H, Levy W, et al. QSPR study about sampling rates of semipermeable membrane devices for monitoring of organochlorine pesticides in Alps air. Chinese Sci Bull, 2011, 56: 1884-1889, doi: 10.1007/s11434-011-4511-2

Semi-permeable membrane devices (SPMD) are popular as passive samplers for sampling persistent organic pollutants (POP) in air since it was introduced by Petty et al. [1] SPMD is typically composed of a flat low-density polyethylene (LDPE) membrane tube filled with triolein. LDPE membrane is described as a nonporous material, but random thermal motions of the polymer chains form small cavities (diameter $0.1 \mathrm{~nm}$ ) in the membrane [2]. The application of SPMD has been summarized in many articles [2-6]. Al-

*Corresponding author (email: zhuxiuhua1@ hotmail.com) though SPMD have been widely used to sample polychlorinated dibenzo-p-dioxins (PCDD), dibenzofurans (PCDF), polychlorinated biphenyls (PCB), and polycyclic aromatic hydrocarbons $(\mathrm{PAH})$, there are few studies focused on sampling of organochlorine pesticides (OCP) in ambient air. Some OCP (e.g. dieldrin, DDT, chlordane, etc.) belong to the "Dirty Dozen" of chemicals whose toxicity, persistence and amounts released are of particular environmental concern [7]. It is well known that OCP were used for many decades and their residual effects are still observed today.

When SPMD sampling is in linear uptake stage, the 
atmospheric concentration of POP, $C_{\text {air }}\left(\mathrm{pg} \mathrm{m}^{-3}\right)$, can be calculated from the sampling rate of the $\operatorname{SPMD}\left(R_{\text {air }}, \mathrm{m}^{3} \mathrm{~d}^{-1}\right.$ $\mathrm{SPMD}^{-1}$ ), the concentrations of POP sequestered by the SPMD $\left(C_{\mathrm{SPMD}}, \mathrm{pg} \mathrm{SPMD}^{-1}\right)$ and the exposure time of the $\operatorname{SPMD}(t$, days) using the following formula [8]:

$$
C_{\text {air }}=C_{\mathrm{SPMD}} /\left(R_{\mathrm{air}} t\right) \text {. }
$$

One of the aims of the present paper was to calculate the $R_{\text {air }}$ of OCP at different sampling sites and to evaluate the feasibility for obtaining $C_{\text {air }}$ of OCP using eq. (1).

Although SPMD have many merits for air monitoring, such as their long-term stability, low cost, and ease of deployment, there is limited published data of $R_{\text {air }}$ during their use [2,7-13]. The $R_{\text {air }}$ measurement for each POP is very expensive, time consuming and there are some problems with limits of detection and equipment.

The quantitative structure-property relationship (QSPR) method provides a convenient tool to predict physicochemical properties of chemicals from only molecular structural information, and this may also provide insight into the main factors that influence physicochemical properties of chemicals [14-17]. $R_{\text {air }}$ was influenced by the molecular weight, the substitution patterns of chlorine in PCB, and $K_{\text {oa }}$ of POP [2,10,11,18].

Another aim of this paper was to study the relationship of the $R_{\text {air }}$ with the structure and properties of OCP. It is expected that an ideal model can be found which can be used to predict the $R_{\text {air }}$ from the structure and properties of OCP. In future, the $R_{\text {air }}$ of many OCP could be predicted from a small number of $R_{\text {air }}$ measurements of OCP by the QSPR model.

\section{Materials and methods}

\subsection{Sampling}

Sampling was conducted at two sites at different altitude. One site was at the Weissfluhjoch (code: $\mathrm{CH}$ ), which is in the central Swiss Alps at $2663 \mathrm{~m}$ above sea level (a.s.l.). The other site was at the top of Mt. Sonnblick (code: AT) at $3106 \mathrm{~m}$ a.s.l. in the eastern Austria Alps. The Monitoring Network in the Alpine Region for Persistent and other Organic Pollutants (MONARPOP) was funded by the EU Interreg III B Alpine Space Programme (Alpine Space) and by the participating partners. A number of ambitious goals have been set for this program. MONARPOP monitors POPs and other organic pollutants with respect to their long-range transport to remote alpine regions, prevalent source directions, loads within the alpine range, regional differences, variation with altitude, present stocks, load bound in forests of the alpine region, and possible biological effects. The project aims to provide information to decision markers. In the future, the evidence gathered during MONARPOP may help to assess the success of the Stockholm POP convention. Detailed information about the project is available in http://www.monarpop.at/downloads/ MONARPOP_Technical_Report.pdf.

Passive samplers were deployed from December 2005 to May 2006. At $\mathrm{CH}$ sampling occurred for $236 \mathrm{~d}$ and the mean temperature was $-5.8^{\circ} \mathrm{C}$, and at AT sampling occurred for $211 \mathrm{~d}$ and mean temperature was $-10.3^{\circ} \mathrm{C}$. The SPMD was a LDPE tube (length $23 \mathrm{~cm}$, width $2.5 \mathrm{~cm}$, thickness $67.5 \mu \mathrm{m}$ ) filled with $0.7 \mathrm{~mL}$ triolein $99 \%$ (Sigma-Aldrich, Taufkirchen, Germany). The passive samplers were heat-sealed in a glove chamber with a nitrogen atmosphere to avoid contamination. The resulting area of the sampler (A) was about $115 \mathrm{~cm}^{2}$. The SPMD were deployed in Stevenson screen boxes of untreated wood $(50 \mathrm{~cm} \times 50 \mathrm{~cm} \times$ $40 \mathrm{~cm}$ ). Then, they were placed $2 \mathrm{~m}$ above the ground at the two high altitude stations. The active air sampling was performed using a low volume sampler (Digitel blower, DPA96). Four glass cartridges filled with $50 \mathrm{~g}$ of XAD resin each were used as absorbers. Each filter cartridge sampled air masses coming from one of three predefined European source regions and an additional one for air masses of undefined origin. The appropriate cartridge was activated via the Internet based on daily meteorological trajectory forecast. Active sampling was conducted from 02.12.2005 to 16.03.2006, and from 16.03.2006 to 06.07.2006 at $\mathrm{CH}$, and from 04.12.2005 to 16.03 .2006 and from 16.03.2006 to 19.07.2006 at AT. The active and passive samplings were carried out almost simultaneously. Further information about the active and passive sampling is available in Levy et al. [19], Moche et al. [20] and Offenthaler et al. [21].

\subsection{Extraction, cleanup, analysis, and quality assurance/quality control (QA/QC)}

The extraction, cleanup, analysis, and QA/QC of SPMD were performed as for PAH treatment [6], but with different ${ }^{13} \mathrm{C}_{12}$-labeled internal standards (Cambridge Isotope Laboratory, Woburn, MA, USA), $\alpha$-hexachlorocyclohexane $(\alpha-$ $\mathrm{HCH}), \gamma-\mathrm{HCH}, \mathrm{p}, \mathrm{p}^{\prime}$-dichloro-diphenyl-trichloroethane (p, $\mathrm{p}^{\prime}-$ DDT), o, $\mathrm{p}^{\prime}$-dichloro-diphenyl-trichloroethane (o, $\mathrm{p}^{\prime}$-DDT), $o, p^{\prime}$-dichloro-diphenyl-dichloroethene (o, $\mathrm{p}^{\prime}$-DDE), transchlordane, cis-chlordane, dieldrin, endosulfan-I, and endosulfan-II were added into cyclohexane at the beginning of the extraction procedure.

For the extraction of the glass cartridges, first ${ }^{13} \mathrm{C}_{12}$ labeled internal standards were added to the XAD resin in the cartridge, and then the cartridge was Soxhlet extracted with $n$-hexane/acetone (3:1) for $24 \mathrm{~h}$. The internal standards, cleanup, analysis, and QA/QC were as mentioned above for SPMD.

\subsection{Descriptors and statistical analysis}

Recently, a semi-empirical, more complete parameter optimization PM6 method [22] has been implemented in the 
MOPAC 2009 package [23]. This method provides satisfactory estimates of molecular properties such as heat of formation and electronic polarizability [24-26]. In this paper, molecular structures of the studied compounds were drawn with CS ChemDraw Ultra 6.0. Then geometry optimizations and quantum-mechanical calculations were performed at the semi-empirical PM6 level with the MOPAC 2009 package [22,23]. A total of 23 molecular descriptors that reflected the overall characteristics of the chemicals were obtained from the MOPAC output files. In addition, two topological descriptors, which were the Kier symmetry index (SOK) and Kier flexibility index (PHI), were included in the QSAR modeling. These were calculated by Dragon (Version 2.1) software and had been used to characterize entropic factors $[27,28]$. Ovality $(\mathrm{Ov})$ was calculated with ChemPropStd which is included in the CS Chem3D Ultra 6.0 program [29]. The molecular structural descriptors are listed in Table 1. For a more detailed explanation of the descriptors, please refer to Todeschini and Consonni [30] and Stewart [23]. The values of the molecular descriptors are provided in the electronic supplementary material (Table S1).

Partial least squares (PLS) regression was adopted because it can be used to analyze data with strongly collinear, noisy, and numerous predictor variables [31]. In this study, the PLS analysis was carried out by Simca-S (Version 6.0, Umetri AB \& Erisoft AB). Simca-S employs "cross validation" to determine the number of PLS components $(A)$. $Q^{2}$ cum is a main statistical parameter of a PLS model, and denotes the cumulative variance of the dependent variable explained by the extracted PLS components. It is a good measure of the predictive power and robustness of the model. When $Q^{2}$ cum of a model is $>0.5$, the model can be considered to be predictive and robust.

In practice, if irrelevant or not significant relevant descriptors are included, the quality of prediction and robustness of the PLS model may decrease, and interpretation of the model becomes difficult. Consequently, it is necessary to eliminate redundant predictor variables and identify important predictor variables. This procedure is called variable selection. The importance of predictor variables, that is, their influence on the response variable can be used as a basis for the variable selection. In Simca-S, this is performed using the variable importance in the projection (VIP). Predictor variables with large VIP are more relevant for explaining the response variable than those with small VIP. If VIP $>1$, the predictor variable has a large influence on the response variable. Based on $Q^{2}$ cum and VIP, a variable selection procedure was performed. At first, a PLS model was developed with all the selected predictor variables. Then one of the predictor variables at a time was removed, and the PLS analysis was repeated with the remaining variables. This step was repeated until each variable had been removed once (and only once). Then $Q_{\text {cum }}^{2}$ of the series of models were compared and the model with the highest $Q_{\text {cum }}^{2}$ was selected for the next step. If several models had the same $Q_{\text {cum }}^{2}$, the model that was obtained by exclusion of the variable with the lowest VIP was adopted. This process was repeated until only two variables were left. The model with the highest $Q^{2}$ cum was selected as the optimal model from all the models obtained [14].

\section{Results and discussion}

\section{1 $R_{\text {air }}$ of SPMD at different sampling sites}

The concentrations of OCP in air obtained by active sampling and OCP accumulation in SPMD are listed in Table 2. Using the $C_{\text {air }}$ and $C_{\text {SPMD }}$ data in Table 2, the $R_{\text {air }}$ (Table 2) of the SPMD for OCP was calculated according to eq. (1).

A $t$-test was carried out to determine whether there was significant difference between the $R_{\text {air }}$ values at two different sampling sites in the same sampling period. Before applying the $t$-test, one-sample Kolmogorov-Smirnov test was used to verify if the $R_{\text {air }}$ values at the two different sampling sites were normally distributed. All statistical tests were performed using SPSS 16.0.

The statistical tests showed that the $R_{\text {air }}$ at the two different sampling sites were normally distributed. The $t$ value was 0.461 which is smaller than $t_{0.05(9)}=2.26$ [32], so there is no significant difference between the $R_{\text {air }}$ obtained from the two different sampling sites. In this way, the $R_{\text {air }}$ of the

Table 1 Theoretical molecular structural descriptors

\begin{tabular}{|c|c|c|}
\hline No. & Descriptors & Descriptions \\
\hline 1 & S0K & Kier symmetry index \\
\hline 2 & PHI & Kier flexibility index \\
\hline 3 & Ov & $\begin{array}{l}\text { The ratio of the molecular surface area to the } \\
\text { minimum surface area }\end{array}$ \\
\hline 4 & $\Delta H_{\mathrm{f}}$ & Standard heat of formation $(\mathrm{kJ})$ \\
\hline 5 & $A_{\mathrm{vdW}}$ & The van der Waals area $\left(\AA^{2}\right)$ \\
\hline 6 & TE & Total energy $(\mathrm{eV})$ \\
\hline 7 & $\mathrm{EE}$ & Electronic energy $(\mathrm{eV})$ \\
\hline 8 & CCR & Core-core repulsion energy $(\mathrm{eV})$ \\
\hline 9 & DE & The dielectric energy $(\mathrm{eV})$ \\
\hline 10 & $V_{\mathrm{vdW}}$ & The van der Waals volume $\left(\AA^{3}\right)$ \\
\hline 11 & IP & The vertical ionization potential $(\mathrm{eV})$ \\
\hline 12 & Mw & Molecular mass (atomic mass units) \\
\hline 13 & ME & Mulliken's electronegativity $(\mathrm{eV})$ \\
\hline 14 & $\mathrm{AH}$ & Parr and Pople's absolute hardness $(\mathrm{eV})$ \\
\hline 15 & $E_{\text {Номо }}$ & $\begin{array}{l}\text { The energy of the highest occupied molecular } \\
\text { orbital }(\mathrm{eV})\end{array}$ \\
\hline 16 & $E_{\text {LUMO }}$ & $\begin{array}{l}\text { The energy of the lowest unoccupied molecular } \\
\text { orbital }(\mathrm{eV})\end{array}$ \\
\hline 17 & $q_{\mathrm{C}}^{-}$ & $\begin{array}{l}\text { The most negative net atomic charges on a carbon } \\
\text { atom (atomic charge unit) }\end{array}$ \\
\hline 18 & $q_{\mathrm{H}}^{+}$ & $\begin{array}{l}\text { The most positive net atomic charges on a hydro- } \\
\text { gen atom (atomic charge unit) }\end{array}$ \\
\hline 19 & $q_{\mathrm{Cl}}^{-}$ & $\begin{array}{l}\text { The most negative net atomic charges on a chlorine } \\
\text { atom (atomic charge unit) }\end{array}$ \\
\hline 20 & $q^{-}$ & $\begin{array}{l}\text { The most negative net atomic charges on a atom } \\
\text { (atomic charge unit) }\end{array}$ \\
\hline 21 & $q^{+}$ & $\begin{array}{l}\text { The most positive net atomic charges on a atom } \\
\text { (atomic charge unit) }\end{array}$ \\
\hline 22 & $\mu$ & The total dipole moment (Deb) \\
\hline 23 & $\alpha$ & Average molecular polarizability (atomic units) \\
\hline
\end{tabular}


Table 2 The $C_{\text {air }}, C_{\mathrm{SPMD}}$ and $R_{\text {air }}$ of OCP

\begin{tabular}{|c|c|c|c|}
\hline Compounds & $\begin{array}{c}C_{\mathrm{SPMD}} \\
\left(\mathrm{pg} \mathrm{SPMD}^{-1}\right)\end{array}$ & $\begin{array}{c}C_{\text {air }} \\
\left(\mathrm{pg} \mathrm{Nm}^{-3}\right)^{\mathrm{a})}\end{array}$ & $\begin{array}{l}R_{\text {air }}\left(\mathrm{Nm}^{3} \text { air }\right. \\
\left.\mathrm{d}^{-1} \mathrm{SPMD}^{-1}\right)\end{array}$ \\
\hline \multicolumn{4}{|l|}{ AT } \\
\hline$\alpha-\mathrm{HCH}$ & 636.0 & 8.3 & 0.4 \\
\hline$\gamma-\mathrm{HCH}$ & 7937 & 217 & 0.2 \\
\hline $\mathrm{p}, \mathrm{p}^{\prime}-\mathrm{DDT}$ & 82.0 & 0.38 & 1.0 \\
\hline$o, p^{\prime}-\mathrm{DDT}$ & 213.0 & 0.4 & 2.6 \\
\hline $\mathrm{o}, \mathrm{p}^{\prime}-\mathrm{DDE}$ & 43.0 & 0.1 & 2.2 \\
\hline trans-Chlordane & 135.0 & 0.4 & 1.7 \\
\hline cis-Chlordane & 251.0 & 0.7 & 1.8 \\
\hline Dieldrin & 338.0 & 1.4 & 1.2 \\
\hline Endosulfan-I & 21239 & 35.8 & 2.8 \\
\hline $\begin{array}{c}\text { Endosulfan-II } \\
\mathrm{CH}\end{array}$ & 1136 & 2.1 & 2.5 \\
\hline$\alpha-\mathrm{HCH}$ & 776.0 & 8.2 & 0.4 \\
\hline$\gamma-\mathrm{HCH}$ & 1172 & 11.3 & 0.4 \\
\hline $\mathrm{p}, \mathrm{p}^{\prime}-\mathrm{DDT}$ & 861.0 & 1.5 & 2.4 \\
\hline $\mathrm{o}, \mathrm{p}^{\prime}$-DDT & 575.0 & 0.9 & 2.7 \\
\hline $\mathrm{o}, \mathrm{p}^{\prime}-\mathrm{DDE}$ & 65.0 & 0.1 & 2.0 \\
\hline trans-Chlordane & 163.0 & 0.5 & 1.3 \\
\hline cis-Chlordane & 330.0 & 0.9 & 1.5 \\
\hline Dieldrin & 475.0 & 2.0 & 1.0 \\
\hline Endosulfan-I & 22056 & 48.9 & 1.9 \\
\hline Endosulfan-II & 1553 & 3.5 & 1.9 \\
\hline
\end{tabular}

a) The air concentration with active sampler was standardized at normal conditions $(\mathrm{N})$ of $1 \mathrm{~atm}$ and $273 \mathrm{~K}$.

SPMD for selected OCP at one sampling site can be substituted using that of the other sampling site for the same sampling period. This means that $R_{\text {air }}$ can be used to calculate $C_{\text {air }}$ no matter where it is obtained as long as the sampling sites have similar characteristics under comparable environmental conditions of deployment of the SPMD, and the same designed of SPMD is used. Therefore, if electricity is available for active sampling at a particular site, OCP can be monitored with active sampling and SPMD passive sampling simultaneously. Thus, the $R_{\text {air }}$ of SPMD for OCP can be calculated. This $R_{\text {air }}$ and eq. (1) can then be used to calculate the $C_{\text {air }}$ of OCP for a site where electricity is not available as long as it has similar characteristics to the first site and the $C_{\mathrm{SPMD}}$ and $t$ are available.

\subsection{QSPR model construction and analysis}

PLS analyses for $R_{\text {air }}$ were performed with all the descriptors. The optimal PLS model obtained by the variable selection procedure was:

$$
\log R_{\mathrm{air}}=b_{0}+b_{1} A_{\mathrm{vdw}}+b_{2} \mathrm{TE}+b_{3} \mu .
$$

The intercept $\left(b_{0}\right)$, the coefficients $\left(b_{1}, \cdots b_{3}\right)$ and the other results of the above PLS regression eq. are summarized in Table 3. These results include the number of data points $(n)$, the number of PLS components $(A)$, the cumulative variance of all the predictor variables, and dependent variable, which are explained by the extracted components $\left(R_{X(\text { adj)(cum) }}^{2}\right.$ and $R_{Y(\text { adj)(cum) }),}^{2} Q_{\text {cum }}^{2}$ and the correlation coefficient between experimental and fitted values $(r)$, respectively.

$$
Q^{2} \text { cum of the optimal models were }>0.818 \text {, which is much }
$$

bigger than 0.5 . This indicates that the model has good predictive ability and robustness, and could be used to estimate $R_{\text {air }}$ values for compounds of this type. In view of difficulties in the measurement of $R_{\text {air }}$, the predicted data could be regarded as an approximation of air sampling rates.

VIP of a predictor variable indicates the influence on the response variable of the predictor variable. From Table 4, it can be seen that $\mu$ and in particular $A_{\mathrm{vdw}}$ and TE are important variables for modeling of $\log R_{\text {air }}$.

The weights of predictor variables $\left(w^{*}\right)$ and weights of response variable $(c)$ of the PLS model are also presented in Table 4. The PLS weights represent how much a single variable contributes in each PLS component to the modeling of $\log R_{\text {air. }}$ Predictor variables which are more important for the $n$th PLS component, have higher $w^{*}[n]$ absolute values. Response variables well modeled by the $n$th PLS component have large $c[n]$ absolute values. From the values of $w^{*}$ in Table 4, it can be seen that the PLS component is mainly relevant to $A_{\mathrm{vdw}}$ and TE. From the coefficients $\left(b_{1}, b_{2}, b_{3}\right)$ of eq. (2) in Table 3 , it can be seen that $A_{\mathrm{vdw}}$ and $\mu$ are positively correlated with $\log R_{\text {air }}$, whereas TE is negatively correlated with $\log R_{\text {air }}$.

The SPMD was developed in Stevenson screen boxes, and because the wind-speed within the Stevenson screen is much lower and less variable than that outside, the affect of difference in the wind-speed on sampling rates could be ignored [33]. It was reported that the sampling rate of SPMD for PCB was affected by steric hindrance of the PCB molecule, and increased ortho-substitution for the same level of chlorination has been found to result in a decreased sampling rate for PCBs $[11,18]$. From eq. (2), it can be seen that the sampling rate of the SPMD for OCP is related to the molecular $A_{\mathrm{vdw}}$. This indicates that like PCB the size of the OCP molecule influences on the sampling rate.

According to the linear solvation energy relationships

Table 3 Results of the QSPR model of $\log R_{\text {air }}$ at different sampling sites

\begin{tabular}{ccc}
\hline Sampling site & $\mathrm{CH}$ & $\mathrm{AT}$ \\
\hline$b_{0}$ & -2.527 & -2.301 \\
$b_{1}$ & $8.383 \times 10^{-3}$ & $4.992 \times 10^{-3}$ \\
$b_{2}$ & $-1.107 \times 10^{-4}$ & $-2.891 \times 10^{-4}$ \\
$b_{3}$ & $1.198 \times 10^{-2}$ & $4.559 \times 10^{-2}$ \\
$n$ & 10 & 10 \\
$A$ & 1 & 1 \\
$R_{\text {Xadj(cum) }}^{2}$ & 0.772 & 0.522 \\
$R_{\text {Yadj(cum) }}^{2}$ & 0.877 & 0.829 \\
$Q_{\text {(cum) }}^{2}$ & 0.874 & 0.818 \\
$r$ & 0.951 & 0.921 \\
\hline
\end{tabular}

Table 4 VIP values and PLS weights in model

\begin{tabular}{llllrr}
\hline & \multicolumn{2}{c}{ VIP } & & \multicolumn{2}{c}{$w^{*} c[1]$} \\
\cline { 2 - 3 } \cline { 5 - 6 } & $\mathrm{CH}$ & $\mathrm{AT}$ & & \multicolumn{1}{c}{$\mathrm{CH}$} & \multicolumn{1}{c}{$\mathrm{AT}$} \\
\hline$A_{\mathrm{vdw}}$ & 1.241 & 0.990 & & 0.719 & 0.575 \\
$\mathrm{TE}$ & 0.925 & 1.049 & & -0.537 & -0.606 \\
$\mu$ & 0.777 & 0.958 & & 0.441 & 0.553 \\
$\log R_{\text {air }}$ & & & & 0.630 & 0.630 \\
\hline
\end{tabular}


(LSER) theory [34], solute solubility and other solvation-dependent properties, XYZ, depend on three types of terms,

$\mathrm{XYZ}=\mathrm{XYZ}_{0}+$ cavity term + dipolar term

+ hydrogen bonding term(s),

where the cavity term characterizes the free energy or enthalpy required to separate the solvent molecules to create a suitably sized cavity for the solute; the dipolar term measures the exoergic effects of solute/solvent dipole-dipole, dipole-induced dipole, and mutually induced dipole interacttions; and the hydrogen bonding term describes the exoergic effects of hydrogen bonding (or Lewis acid/base) complexation between the solute and the solvent $[34,35]$. The partition of OCP molecules between air and the SPMD could be analyzed by the theory of LSER theory. $A_{\mathrm{vdw}}$ and TE may represent non-specific intermolecular interactions or the energy required for cavity-formation in dissolution of OCP into triolein of the SPMD. The descriptor $\mu$ is the dipolar term in eq. (3), which is related to polar interaction of the molecules. Although the altitudes of the two sampling sites were different, all $\log R_{\text {air }}$ can be expressed with eq. (2). This means that the sampling rates of the SPMD for OCP that can enter into the SPMD are mainly related to the intermolecular interactions between OCP and triolein in the SPMD. For the defined SPMD area, the stronger the intermolecular interactions are, the higher the influence on the air sampling rate is.

The predicted and experimental $\log R_{\text {air }}$ from eq. (2) are plotted in Figure 1. From this figure it can be seen that the predicted $\log R_{\text {air }}$ values are consistent with the experimental values.

The results from this study indicate that there is the potential to predict a large number of $R_{\text {air }}$ of OCP from the established model. In addition the use of SPMD as passive air samplers could become more widespread among sites with similar climatological conditions if active sampling is available at a reference site. There is a potential for global deployment of these samplers, which would permit estimation of atmospheric concentrations in remote areas where it

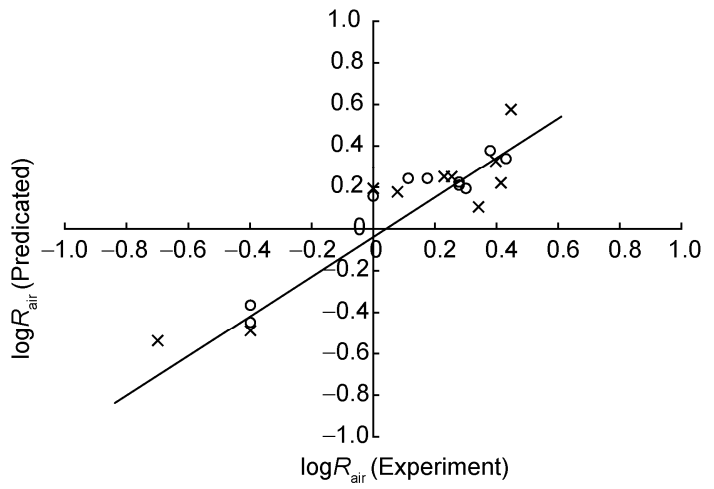

Figure 1 Plot of predicted $\log R_{\text {air }}$ values versus experimental values (०, $\mathrm{CH} ; \times, \mathrm{AT})$. is not possible to install active air monitoring equipment or an electrical supply.

\section{Conclusions}

The $R_{\text {air }}$ derived for a set of OCP at one site were not significantly different from those derived at another site with similar environmental conditions. The $R_{\text {air }}$ of OCP with the SPMD could be predicted from their related molecular quantum chemical properties, the total energy, the van der Waals area and the total dipole moment of the molecule. The main factors influencing $R_{\text {air }}$ were intermolecular interactions and the energy required for cavity-formation in dissolution of OCP into triolein of the SPMD.

We would like to thank the Swiss Federal Office for the Environment (FOEN-BAFU) for financial support. The authors thank the following colleagues for basic work of site selection and sampling: N. Kräuchi (Swiss Research Centre for Forests, Snow and Landscape), M. Kirchner (Helmholtz Zentrum München - German Research Center for Environmental Health) as well as G. Schauer and M. Staudinger from the Austrian Central Institute for Meteorology and Geodynamics (ZAMG) for their support during active air sampling. This work was supported by the National Natural Science Foundation of China (20877011), the State Key Laboratory of Environmental Chemistry and Ecotoxicology, Research Center for Eco-Environmental Sciences, Chinese Academy of Sciences (KF2009-17), the Key Laboratory of Industrial Ecology and Environmental Engineering, China Ministry of Education (0802) and Scientific Research Foundation for Returned Overseas Chinese Scholars. The Monitoring Network in the Alpine Region for Persistent and other Organic Pollutants, MONARPOP, was funded by the EU Interreg III B Alpine Space Programme (Alpine Space) and by the participating partners.

1 Petty J D, Huckins J N, Zajicek J L. Application of semipermebiale membrane devices (SPMDs) as passive air sampling. Chemosphere, 1993, 27: 1609-1624

2 Huckins J N, Petty J D, Booij K. Monitors of Organic Chemicals in the Environment-Semipermeable Membrane Device. New York: Springer Science, 2006

3 Esteve-Turrillas F A, Pastor A, Yusà V, et al. Using semi-permeable membrane devices as passive samplers. Trends Anal Chem, 2007, 26: 703-712

4 Esteve-Turrillas F A, Yusà V, Pastor A, et al. New perspectives in the use of semipermeable membrane devices as passive samplers. Talanta, 2008, 74: 443-457

5 Zhu X, Pfister G, Henkelmann B, et al. Simultaneous monitoring of PCDD/ Fs and PCBs in contaminated air with semipermeable membrane devices and fresh spruce needles. Chemosphere, 2007, 68: 1623-1629

6 Zhu X, Pfister G, Henkelmann B, et al. Simultaneous monitoring of profiles of polycyclic aromatic hydrocarbons in contaminated air with semipermeable membrane devices and spruce needles. Environ Pollut, 2008, 156: 461-466

7 Yu G, Huang J. One Hundred Questions About the Knowledge of POPs (in Chinese). Beijing: Chinese Environmental Science Press, 2005. 5-7

8 Ockenden W A, Sweetman A J, Prest H F, et al. Toward an understanding of the global atmospheric distribution of persistent organic pollutants: The use of semipermeable membrane devices as time-integrated passive samplers. Environ Sci Technol, 1998, 32: 2795-2803

9 Bartkow M E, Huckins J N, Mu J F. Field-based evaluation of semipermeable membrane devices (SPMDs) as passive air samplers 
of polyaromatic hydrocarbons (PAHs). Atmos Environ, 2004, 38: 5983-5990

10 Liu G Q, Zhang G, Li J, et al. Spatial distribution and seasonal variations of polycyclic aromatic hydrocarbons (PAHs) using semipermeable membrane devices (SPMD) and pine needles in the Pearl River Delta, South China. Atmos Environ, 2006, 40: 3134-3143

11 Ockenden W A, Prest H F, Thomas G O, et al. Passive air sampling of PCBs: Field calculation of atmospheric sampling rates by trioleincontaining semipermeable membrane devices. Environ Sci Technol, 1998, 32: 1538-1543

12 Shoeib M, Harner T. Characterization and comparison of three passive air samplers for persistent organic pollutants. Environ Sci Technol, 2002, 36: 4142-4151

13 van Drooge B L, Grimalt J O, Booij K, et al. Passive sampling of atmospheric organochlorine compounds by SPMDs in a remote high mountain area. Atmos Environ, 2005, 39: 5195-5204

14 Ding G, Chen J, Qiao X, et al. Quantitative relationships between molecular structures, environmental temperatures and solid vapor pressures of PCDD/Fs. Chemosphere, 2006, 62: 1057-1063

15 Zhu X H, Wang W, Schramm K W, et al. Prediction of Kováts retention indices for thiols using quantumchemical and physicochemical descriptors. Chromatographia, 2007, 65: 719-724

16 Chen J W, Harner T, Ding G H, et al. Universal predictive models on octanol-air partition coefficients at different temperatures for persistent organic pollutants. Environ Toxicol Chem, 2004, 23: 2309-2317

17 Li X H, Chen J W, Zhang L, et al. The Fragment constant method for predicting octanol-air partition coefficients of persistent organic pollutants at different temperatures. J Phy Chem Ref Data, 2006, 35 : 1365-1384

18 Lohmann R, Corrigan B P, Howsam M, et al. Further Developments in the use of semipermeable membrane devices (SPMDs) as passive air samplers for persistent organic pollutants: Field application in a spatial survey of PCDD/Fs and PAHs. Environ Sci Technol, 2001, 35: 2576-2582

19 Levy W, Henkelmann B, Pfister G, et al. Monitoring of PCDD/Fs in a mountain forest by means of active and passive sampling. Environ Res, 2007, 105: 300-306

20 Moche W, Bassan R, Belis C A, et al. Source region specific ambient air sampling of POP in the Alps. Organohalogen Compounds, 2008, 70: $361-364$
21 Offenthaler I, Jakobi G, Kaiser A, et al. Novel sampling methods for atmospheric semi-volatile organic compounds (SOCs) in a high altitude alpine environment. Environ Pollut, 2009, 157: 3290-3297

22 Stewart J J P. Optimization of parameters for semiempirical methods $\mathrm{V}$ : Modification of NDDO approximations and application to 70 elements. J Mol Model, 2007, 13: 1173-1213

23 Stewart J J P. MOPAC 2009 Version 8.318W. Stewart computational chemistry Colorado Springs CO USA, 2008, http://www. OpenMOPAC. net [01-12-2008]

24 Alparone A, Librando V, Minniti Z. Validation of semiempirical PM6 method for the prediction of molecular properties of polycyclic aromatic hydrocarbons and fullerenes. Chem Phys Lett, 2008, 460: $151-154$

25 Puzyn T, Suzuki N, Haranczyk M, et al. Calculation of quantummechanical descriptors for QSPR at the DFT Level: Is it necessary? J Chem Inf Model, 2008, 48: 1174-1180

26 Puzyn T, Mostrag A, Suzuk N, et al. QSPR-based estimation of the atmospheric persistence for chloronaphthalene congeners. Atmos Environ, 2008, 42: 6627-6636

27 Kier L B. Inclusion of symmetry as a shape attribute in Kappa index analysis. Quant Struct-Act Rel, 1987, 6: 8-12

28 Kier L B. An index of molecular flexibility from Kappa shape attributes. Quant Struct-Act Rel, 1989, 8: 221-224

29 Connolly M L. The molecular surface package. J Mol Graphics, 1993, 11: 139-141

30 Todeschini R, Consonni V. Handbook of Molecular Descriptors. Weinheim: Wiley-VCH Verlag, 2000

31 Wold S, Sjöström M, Eriksson L. PLS-regression: A basic tool of chemometrics. Chemometr Intell Lab, 2001, 58: 109-130

32 Xi T, Sun Y, Liu X. Environmental Monitoring (in Chinese). Beijing: Higher Education Press, 2004. 424

33 Ockenden W A, Corrigan B P, Howsam M, et al. Futher developments in the use of semipermeable membrane devices as passive air samplers: Application to PCBs. Environ Sci Technol, 2001, 35: 45364543

34 Kamlet M J, Doherty R M, Abbound J L, et al. Solubility-A new look. Chemtech, 1986, 16: 566-576

35 Kamlet M J, Taft R W. Linear solvation energy relationships. Local empirical rules or Fundamental laws of chemistry? A reply to the chemometricians. Acta Chem Scand B, 1985, 39: 611-628

Open Access This article is distributed under the terms of the Creative Commons Attribution License which permits any use, distribution, and reproduction in any medium, provided the original author(s) and source are credited.

\section{Supporting Information}

Table S1 Values of the molecular descriptors for OCPs

The supporting information is available online at csb.scichina.com and www.springerlink.com. The supporting materials are published as submitted, without typesetting or editing. The responsibility for scientific accuracy and content remains entirely with the authors. 